\title{
Making accessibility analyses accessible: $A$ tool to facilitate the public review of the effects of regional transportation plans on accessibility
} \section{Aaron Goluba}

Arizona State University

\section{Glenn Robinson}

Morgan State University

\author{
Brendan Nee \\ BlinkTag, Inc
}

\begin{abstract}
The regional transportation planning process in the United States has not been easily opened to public oversight even after strengthened requirements for public participation and civil rights considerations. In the effort to improve the public review of regional transportation plans, this paper describes the construction of a proof-of concept web-based tool designed to analyze the effects of regional transportation plans on accessibility to jobs and other essential destinations. The tool allows the user to analyze disparities in accessibility outcomes by demographic group, specifically income and race, as required by civil rights-related planning directives. The tool makes cumulative-opportunity measures of the number of essential destinations reachable within certain times by public transit and automobile. The tool is constructed to analyze the San Francisco Bay Area's 2005 regional transportation plan. Users can choose to make measures for a particular neighborhood or for all neighborhoods in the region with certain demographic characteristics. Two example analyses are shown with an interpretation and discussion of calculator outputs.
\end{abstract}

\section{Introduction}

For decades the regional transportation planning process had limited participation from the wider public and was largely an activity of experts (Rose, 1990). In the United States since the 1980s, this has changed as the idea of public participation and oversight has been transformed by the civil-rights and environmental movements. These movements eventually produced legislation and policies that strengthened the requirements for public participation in planning processes, especially those pertaining to urban transportation systems and especially those concerning impacts on low-income and minority communities. Legislation notwithstanding, the regional transportation planning process in the United States has not been easily opened to public oversight. This is likely due to a combination of a lack of effort from regional planning agencies and the highly technical nature of regional transportation modeling. There have been attempts to shed some light inside regional travel modeling (Beimbaum, 2006), but very few have attempted to allow a detailed public evaluation of the outcomes of regional transportation plans (see Forkenbrock and Sheeley, 2004). The best cases of equity analyses of regional plans produce regionwide metrics and do not allow for more tailored analysis by the public (see Southern California Association of Governments, 2008; Metropolitan Transportation Commission, 2009; and Atlanta Regional Commission, 2011). To address this deficien$\mathrm{cy}$, this paper describes the construction of a proof-of concept web-based tool to analyze the effects of regional transportation plans on accessibility to jobs and other essential destinations for different neighborhoods and populations.

We begin by exploring the motivations for improving public evaluation of regional transportation plans with a specific coverage of the environmental justice regulations including specific requirements for public participation in transportation planning. We then explore the construction of the web-based tool, herein called the "accessibility calculator," beginning with some background into the accessibility measures it employs. The paper then presents example analyses for all neighborhoods with more than 40 percent African-American households and all neighborhoods with more than 50 percent of households with incomes below 200 percent of the federal poverty line.

\section{Motivation}

Transportation shapes the spaces around us and the way we can access important destinations beyond our immediate surroundings. In modern urban settlements where uses are dispersed in space, a lack of transportation can mean a lack of opportunities for work, school, recreation, and social interaction, profoundly impacting the prospects for communities and individuals (Ong and Blumenberg, 1998; Ihlanfeldt and Sjoquist, 1998; Taylor and Ong, 1995; Sanchez et al., 2003; Lucas, 2006). Like many other aspects of urban infrastructure and services, access to transportation is unequally distributed — often significantly along class and racial dimensions - and transportation has always been a key battlefield in the struggle for just policies and a

a aaron.golub@asu.edu 
fair distribution of the benefits of public investments in urban development (Bullard, 2004; Bullard and Johnson, 1997; Pucher, 1982). It was a well-known transportation struggle - the anti-segregation bus boycotts in Montgomery, Alabama, in late 1955-that sparked the modern civil-rights movement in the United States. This has turned into concerns for both the distribution of the benefits and burdens of transportation systems, as well as for the inclusiveness of the transportation planning process. The planning process has been closed to public oversight until only recently, though many communities still feel shut out (Denmark, 1998).

These disparities of process and outcomes led to a series of codified standards by which these differences can be measured, mitigated, and prevented. These obligations arise under Title VI of the Civil Rights Act of 1964, the 1994 "Environmental Justice" Executive Order 12898 entitled "Federal Actions to Address Environmental Justice in Minority Populations and Low-Income Populations" (herein EJ Order), and in various federal surface transportation statutes. Here, we briefly review these rules. Title VI of the Civil Rights Act of 1964 provides that:

"No person in the United States shall, on the ground of race, color, or national origin, be excluded from participation in, be denied the benefits of, or be subjected to discrimination under any program or activity receiving Federal financial assistance." (42 U.S.C. $\$ 2000$ d, emphasis added.)

The law pertains not only to the substantive benefits from transportation investments, such as the quantity of transit service, but also to the inclusiveness of the decision-making process itself. A central goal of Title VI is to "[p]romote the full and fair participation of all affected populations in transportation decision making." (FTA Circular 4702.1B, ch. II, $\$ 1$ (b).)

Like Title VI, the U.S. Department of Transportation (DOT) Order 5610.2(a) implementing the EJ Order prohibits actions that cause "disproportionately high and adverse effect on minority and low-income populations," ( $4(\mathrm{~b})$ ) or the "the denial of, reduction in, or significant delay in the receipt of, benefits of DOT programs, policies, or activities." (Appendix $1(\mathrm{f})$ ). The EJ Order includes a specific requirement that regional and local agencies prepare and act on an equity analysis before making a decision with equity impacts. This enables the agency to "identify the risk of discrimination early in the development of the program, policy or activity so that positive corrective action can be taken." (FHWA Order 6640.23 [1998], 8(c)) In order to do this, agencies are required to: "provide meaningful opportunities for public involvement by members of minority populations and low-income populations during the planning and development of programs, policies, and activities (including the identification of potential effects, alternatives, and mitigation measures)." (DOT Order 5610.2(a), $55(\mathrm{~b})(1))$

Following from these requirements, we can see that the need to improve public oversight into the distribution of the benefits of the regional transportation plan (RTP) is motivated by more than a simple desire to improve the planning process; it is actually dictated by the various rules requiring proactive public oversight. This project was funded by the Office of Civil Rights of the Federal Transit Administration to improve the inclusiveness of planning.

In this project we focus on evaluating the effects of an RTP investment program. RTPs create benefits unevenly across a region, and thus their contents are subject to public review and environmental analysis. Scholars have investigated the unequal nature of accessibility benefits from investment programs (e.g., Manaugh and El-Geneidy, 2012; van Wee and Geurs, 2011; Lucas, 2006; and Curtis and Scheurer, 2010) and some have specifically analyzed the effects of RTPs on equity outcomes (e.g., Southern California Association of Governments, 2008; Metropolitan Transportation Commission, 2009; Purvis, 2000; Atlanta Regional Commission, 2011; and Pfeffer et al., 2002), and others have proposed standards of fairness by which to judge distributions of accessibility benefits from RTPs (e.g., Martens, 2012; and Martens et al., 2012). Building on this work, we developed a tool to analyze the disparities in RTP outcomes by neighborhood and demographic group, specifically income and race, as required by civil rights considerations. The tool must be usable by the nonexpert public so that early, continuous, and transparent analysis can be carried out by communities in consultation with the metropolitan planning organization (MPO), as required by the DOT order. In this way, we hope to not only improve the planning process in response to the directives and rules presented above but also to illustrate new approaches to accessibility analyses that might yield new forms of equity measures and analysis tools. Communities protected by the Civil Rights Act and the EJ Order and ensuing directives should be able to understand how a project's proposals impact specifically on them, and thus how the MPO might mitigate these impacts where significant. In the following sections, we introduce the tool and how it works, followed by two example analyses for the 2005 RTP from the San Francisco Bay Area. 


\section{The accessibility calculator}

Before exploring how the calculator works, we discuss the basic approach to accessibility used to create it. The calculator can be accessed at: http://ejkit.com/the-toolkit/ej-analysis-tools/ accessibility-calculator/prototype.

\section{$4 \quad$ Calculator background}

This tool helps communities, planners, and public officials to understand the impact of transportation improvements on neighborhoods, communities, and individuals while also making comparisons between them. Transportation network improvements result from investments planned in the RTP. Often, many different RTP investment options, herein called scenarios, are proposed for consideration within the planning process. The accessibility calculator measures and compares the impact of each scenario on accessibility.

The core accessibility calculation uses the cumulativeopportunity (or continuous-measure) approach and sums the number of essential destinations reachable within certain times by transit and automobile (Wachs and Kumagai, 1973; El-Geneidy and Levinson, 2006). This is particularly useful in describing how well the transportation network works in relation to the distribution of destinations and how they serve the transportation needs for particular subgroups. It is also perhaps the most simple to construct from the typical travel time, demographic, and destination datasets available from city or regional planning agencies. There are some drawbacks to such simple measures, including the fact that significant destinations outside of the region are left out, meaning that interregional accessibility issues are not captured. For a broader discussion and comparison of accessibility measures see Geurs and Ritsema van Eck (2001), Geurs and van Wee (2004), Handy and Niemeier (1997), El-Geneidy and Levinson (2006), and Martens and Golub (2012).

Accessibility measures are made in the tool for two kinds of analyses — one for a particular neighborhood and one for all neighborhoods in the region with certain characteristics. For a specific neighborhood, the following calculations are included:

1. Sum the total number of essential destinations (jobs, jobs of certain types, schools, medical facilities, etc.) reachable within certain time bands $(15,30,45 \mathrm{~min}$ utes) by public transit and automobile

2. Compare this measure with all other neighborhoods

3. Compare this measure for the various future regional transportation scenarios
For a group of neighborhoods with a certain demographic characteristic, the following calculations are included:

1. Sum the total, and average, number of essential destinations (jobs, jobs of certain types, schools, medical facilities, etc.) reachable within certain time bands $(15,30,45$ minutes) by public transit and automobile from all neighborhoods with the specified characteristic (e.g., more than 50 percent low-income)

2. Compare this measure with the balance of the neighborhoods and all neighborhoods

3. Compare this measure for the various future regional transportation scenarios

\section{Case application: San Francisco Bay Area}

The main goal of this project is to develop an example tool that can be replicated easily by any MPO. Thus, the tool uses data and information available to any MPO resulting from its regional modeling efforts. Through contacts at the Metropolitan Transportation Commission, the MPO for the nine-county San Francisco Bay Area, and we were able to acquire input and output data from the 2005 RTP regional travel model runs. The 2005 RTP, called Transportation 2030 was developed between 2003 and 2005 to guide investments for the 25-year period from 2005 to 2030 (MTC 2005). Regional modeling efforts to analyze the impacts of different investment scenarios were made to support the development of the RTP investment recommendations. These models produce travel impacts for each scenario, which can then be used in our tool. A general description of the five scenarios included in our tool can be found in Table 1 .

\section{Accessibility calculator structure}

At its core, the accessibility calculator uses transportation and demographic data to create accessibility measures for each neighborhood in the region. These outputs are assembled in a database that will allow users to analyze the accessibility of different neighborhoods. The tool is managed through a frontend user query interface. The interface then displays output through result tables and statistical comparisons. Figure 1 shows the overall layout of the accessibility calculator. The sections that follow will present the basic structure of the databases and the user interface. 
Table 1: The five regional scenarios included in the accessibility analysis tool

\begin{tabular}{|l|l|}
\hline Scenario & Description \\
\hline Financially Constrained & Base year transportation system, travel times and demographic and land-use data are used \\
\hline No Project & $\begin{array}{l}\text { Base year transportation system plus projects in advanced stages of development, plus proj- } \\
\text { ects developed with funding reasonably available over the 25-year period. Ongoing transpor- } \\
\text { tation revenues from local, county, state, and federal sources are assumed to continue. Those } \\
\text { that sunset during the period are assumed not to be renewed. Future year (2030) demo- } \\
\text { graphics and land-use changes are included. }\end{array}$ \\
\hline Project & $\begin{array}{l}\text { Base year transportation system plus projects only in advanced stages of planning with full } \\
\text { funding guarantees. Future year (2030) demographics and land-use changes are included. }\end{array}$ \\
\hline Transit Defined & $\begin{array}{l}\text { Base year transportation system plus projects in advanced stages of development, plus proj- } \\
\text { ects developed with funding reasonably available over the 25-year period. Ongoing trans- } \\
\text { portation revenues from local, county, state, and federal sources are assumed to continue. } \\
\text { Those sources that sunset during the period are assumed to be renewed, and other funding } \\
\text { sources that are reasonable and supported by districts and agencies within the MTC area } \\
\text { are also assumed. A HOT lane network is implemented in this scenario. Future year (2030) } \\
\text { demographics and land-use changes are included. }\end{array}$ \\
\hline $\begin{array}{l}\text { This scenario was proposed by a local transit advocacy organization called Transportation So- } \\
\text { lutions Defense and Education Fund (TRANSDEF) and was included in the RTP analysis } \\
\text { as part of a legal settlement with MTC. This "smart-growth" scenario limits roadway expan- } \\
\text { sion and assumes regional population growth occurs within or very near established urban } \\
\text { areas and public-transit-supported areas. Future year (2030) demographics are included. }\end{array}$ \\
\hline
\end{tabular}

Source: MTC (2005a) p. 1-2 to 1-3, Transdef (2012)

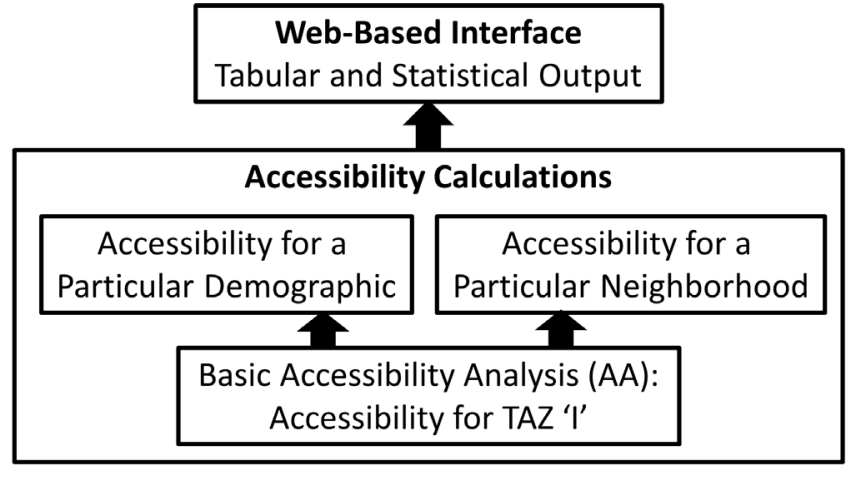

Figure 1: Overall structure of accessibility calculator and interface

\section{Data requirements}

Within most regional transportation modeling systems, the urban area is divided into traffic analysis zones (TAZs), which become the basic unit of analysis in the tool. TAZs are roughly equivalent to census tracts and are slightly larger than typical neighborhoods. The data requirements fall into two types: the demographic and land-use data for each TAZ, herein called TAZ data, and the TAZ-to-TAZ travel times for transit and automobiles, herein called transit and auto "skims." (Additional geographic information system, or GIS, files to represent the TAZ geographies, road and transit networks and other geographic features for the website interface may be needed, but are not involved directly in the calculator and will not be discussed further.) The TAZ data contains all of the information concerning demographics and numbers and types of land uses contained in each TAZ. Demographic data is compiled by the Association of Bay Area Governments and MTC. The destination data is created by MTC using the InfoUSA land-use databases and was translated by MTC into the TAZ system. Future land-use assumptions vary between the scenarios and are captured in the TAZ data files. The skims contain TAZ-toTAZ travel time for every TAZ-to-TAZ pair, and these times differ between the scenarios because of the different transportation investments. The skim files were produced by model runs performed by MTC. Though there are criticisms of the accuracy of travel skims for public transit systems produced using regional models (e.g., Benenson et al., 2011; Tribby and Zandbergen, 2012; Mavoa et al., 2012), we wanted to focus on the data most readily available to MPOs for this initial tool development. More advanced tools for travel-time estimation could be integrated in later efforts.

\section{Basic accessibility calculation}

At the core of the tool is the measure of accessibility for each TAZ to destinations within each reachable TAZ within a given time, T. Those reachable TAZs contain certain numbers of jobs, facilities, etc. The basic accessibility analysis calculations steps are shown in Figure 2 below. 


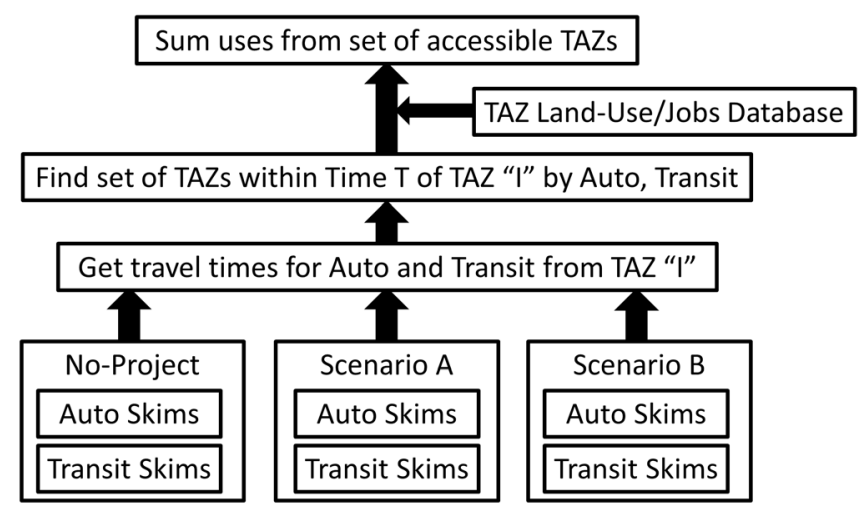

Figure 2: Basic accessibility analysis calculation for TAZ 'I'

The output from the basic accessibility analysis calculation is a dataset for each scenario, showing the total destinations reachable for each TAZ. In equation form, the accessibility calculation goes as follows:

$$
\mathrm{A}_{\text {Dams } T}=\sum_{\mathrm{G}} \mathrm{A}_{\text {iams } T}, \mathrm{G}=\left\{i \mid \mathrm{d}_{i} \geq D\right\}
$$

Where A is the accessibility for neighborhood (TAZ) n, for destination type a (e.g., manufacturing jobs) for mode m, for scenario $s$, for travel-time band T. J is the set of TAZs within travel time $\mathrm{T}$ of TAZ $\mathrm{n}$ for mode $\mathrm{m}$ for scenario $\mathrm{s}$. From here, the calculation is performed for a particular neighborhood or for all neighborhoods with a particular demographic.

Accessibility for particular neighborhood (TAZ ' $n$ ')

To analyze the accessibility for a particular neighborhood, the accessibility database generated from the basic calculator is queried for the accessibility measures from the selected TAZ, and all TAZs. An interface might have a map, where users select their neighborhood, which then automatically proceeds to the calculator. (Current versions don't link these directly.) When the TAZ number is shown on the map, it can be entered into the menu shown circled in Figure 3.

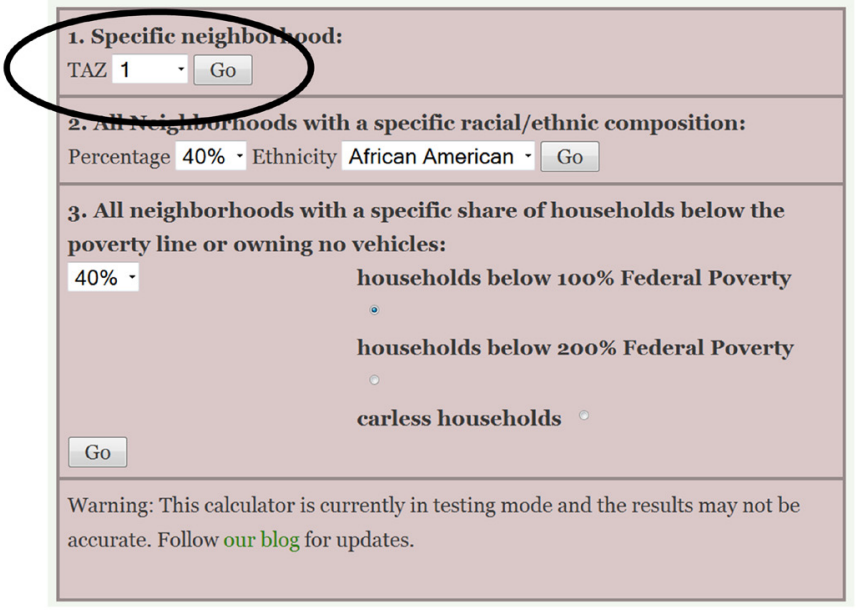

Figure 3: Menu to select specific neighborhood for analysis
Clicking 'go' creates the output page, an example of which is shown below in Figure 4. Tabular outputs for each type of destination now extend down below the input menu.

Figure 5 focuses on the tabular output with numbers pointing to particular items. The database of accessibility includes various types of "essential destinations." Accessibility tables for different types of destinations are placed below the input menu. Thus, in any analysis, one can scroll down to look at the accessibility to food stores, heath facilities, social services, elementary schools, etc. Some of these "essential destinations" are facilities, such as elementary schools, and others, such as "trade," are numbers of jobs of that classification. For facilities, two kinds of outputs are given, the total number of facilities and the number of jobs in these facilities. Both are important because the number of facilities shows the availability of the service, but the total number of jobs indicates the size of the facilities. For example, the number of food stores indicates basic availability, but the numbers of jobs in food stores indicates whether they are corner "beer and wine" stores or larger fullservice groceries.

Item one refers to the columns of accessibilities for the selected neighborhood, TAZ \#10. The top row of numbers: $5028,14,724,26,306$, etc. refer to the number of jobs in food stores accessible by automobile within 15, 30, and 45 minutes, respectively, for the 2000 base scenario. Item two refers to the columns of average accessibilities for all 1454 neighborhoods in the region to help facilitate a comparison with the selected neighborhood.

Item three lists the five RTP scenarios being evaluated. Item four shows how the results of a particular scenario are presented in terms of auto, transit, and "composite" accessibility. These are the numbers of destinations reachable within the different time bands by these travel modes. The composite accessibility takes into account a neighborhood's automobile availability and computes one accessibility from a combination of the automobile and public transit numbers according to the following:

$$
\mathrm{A}_{\text {naCOMPsT }}=\mathrm{X} \cdot \mathrm{A}_{\text {naTransitsT }}+(1-\mathrm{X}) * \mathrm{~A}_{\text {naAUTOsT }}
$$

where $\mathrm{X}$ is the fraction of households in TAZ $\mathrm{n}$ without an automobile. 


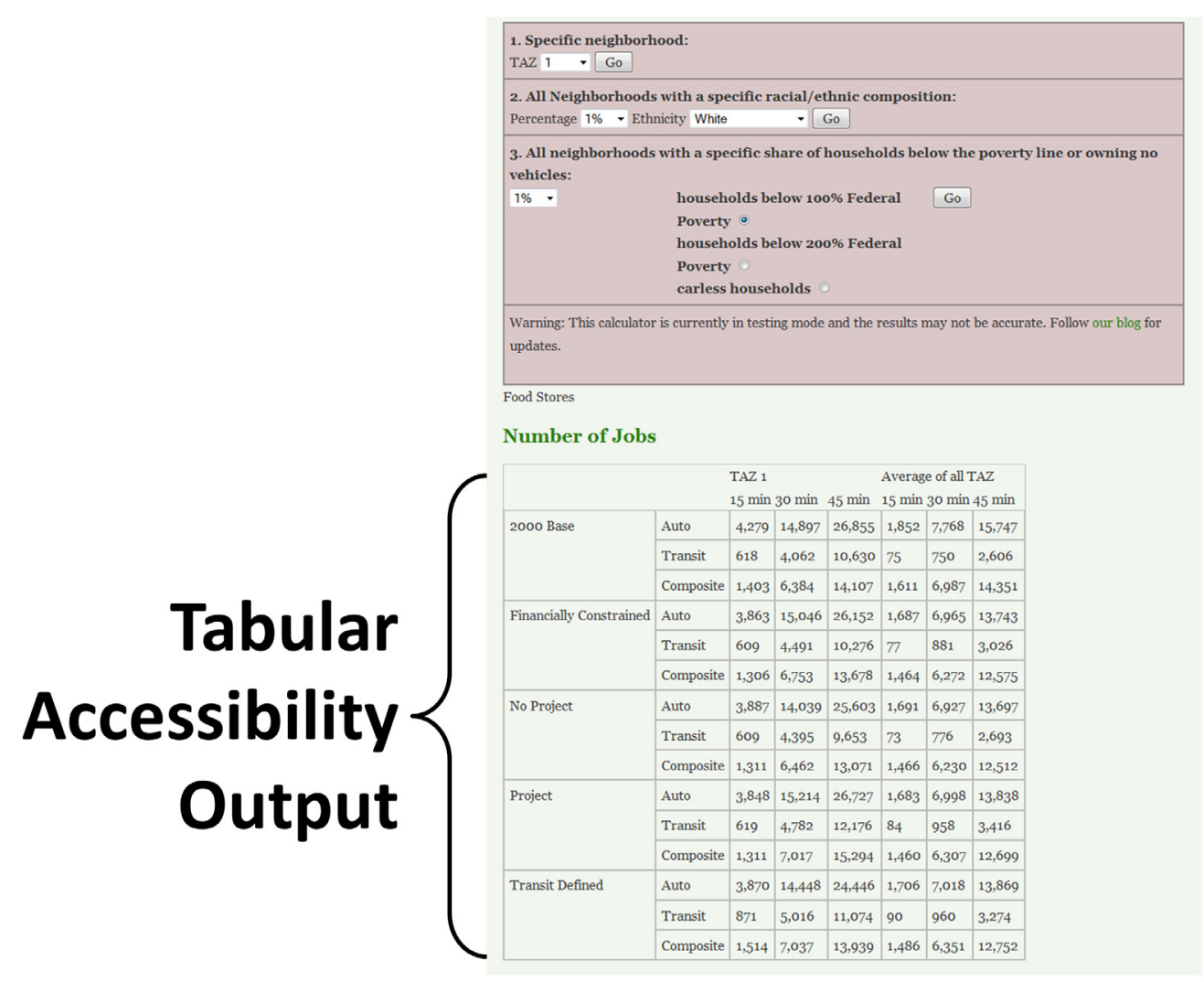

Figure 4: Example output from specific neighborhood analysis

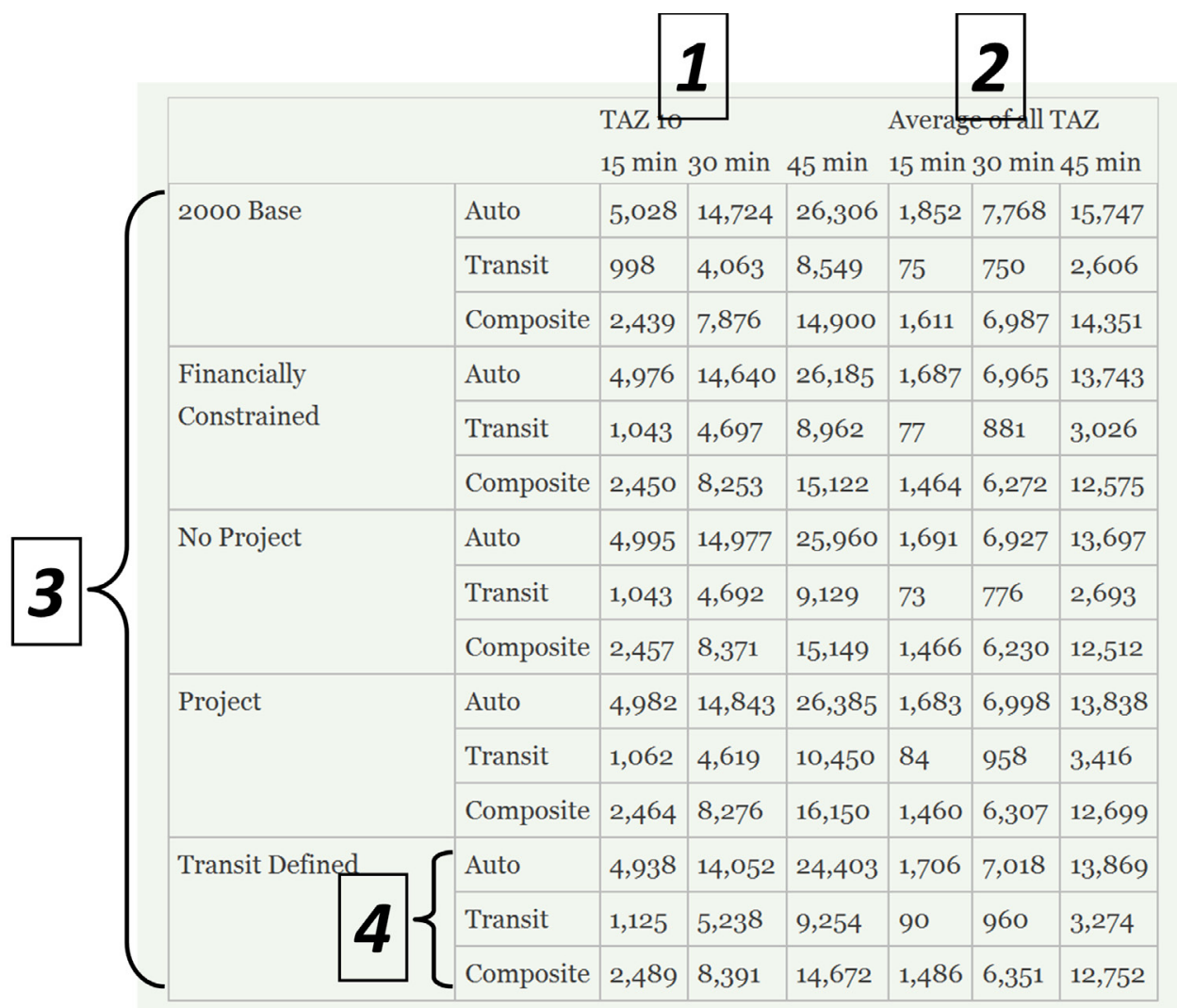

Figure 5: Tabular output for particular neighborhood accessibility analysis 


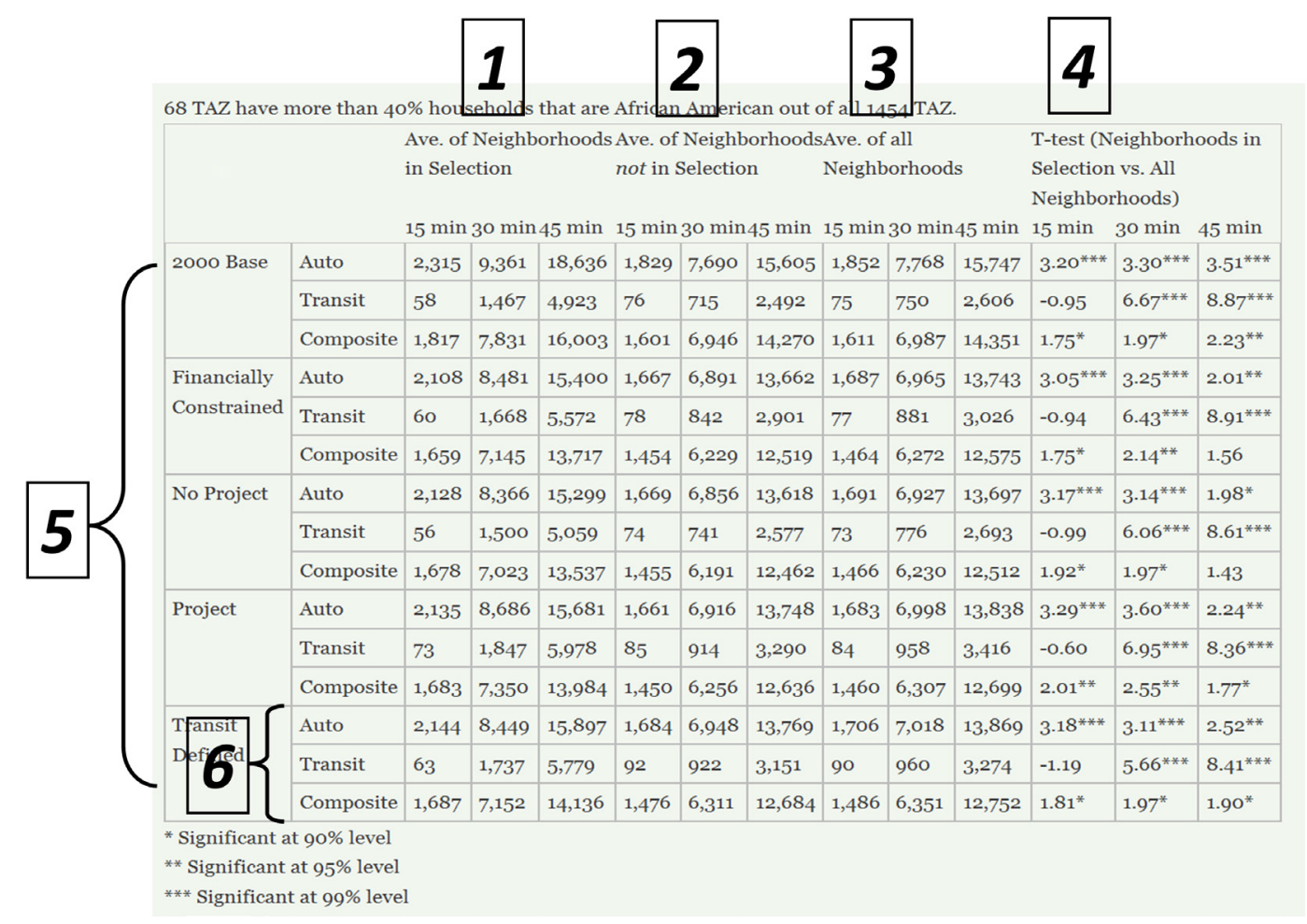

Figure 6: Output for analysis of neighborhoods with at least 40 percent African-American households

\section{$9 \quad$ Analyzing a selection of neighborhoods by characteristics}

To analyze the accessibility for all neighborhoods with a particular demographic, the TAZ demographic database is used to generate a list of TAZs that meet the standard chosen by the user, such as " $>50$ percent low-income" or " $<25$ percent white." From there, the accessibility for all of the TAZs meeting the chosen characteristic are chosen and summed. The calculation is made as follows:

where $\mathrm{D}$ is the demographic requirement, and $\mathrm{G}$ is the set of all TAZs meeting that requirement. Comparisons can then be made between the average accessibility for the chosen group and the average for all TAZs in the region using a t-test.

The two menus number two and number three in the calculator (shown in Figure 3) are both used for analyzing selections. Here, we will step through an analysis and discuss the various outputs. With the first pull-down menu users can choose the percent of the neighborhood population they wish to represent the demographic group they want to investigate. The next menu allows them to choose that demographic group. In the example, 40 percent and African-American are chosen, which means that any neighborhood where 40 percent or more of the households are African-American will be included in the selection.

Figure 6 below shows the output for the 40 percent African-American selection made above, scrolling to the table showing accessibility to food stores (by number of jobs). Note also that 68 TAZs have more than 40 percent households that are African American out of all 1454 TAZs.

Item one refers to the column of average accessibility measures for the 68 selected neighborhoods. These numbers have the same meanings as those discussed above. For example, for the 2000 base scenario, the 68 neighborhoods in the selection have an average of 2315 food-store jobs reachable to them within 15 minutes by automobile. Item two refers to the column of accessibility averages for all of the neighborhoods not in the selection. There are 1386 such neighborhoods. Item three refers to the column of accessibility averages for all of the 1454 neighborhoods in the Bay Area.

Item 4 refers to a column of "T-scores," which measure the statistical significance of the differences between the accessibility measures for the neighborhoods in the selection and all neighborhoods. Items five and six show again the same scenarios and travel modes, which were explained earlier. Scrolling down the page shows the table for the food stores, by number of facilities instead of by jobs. 


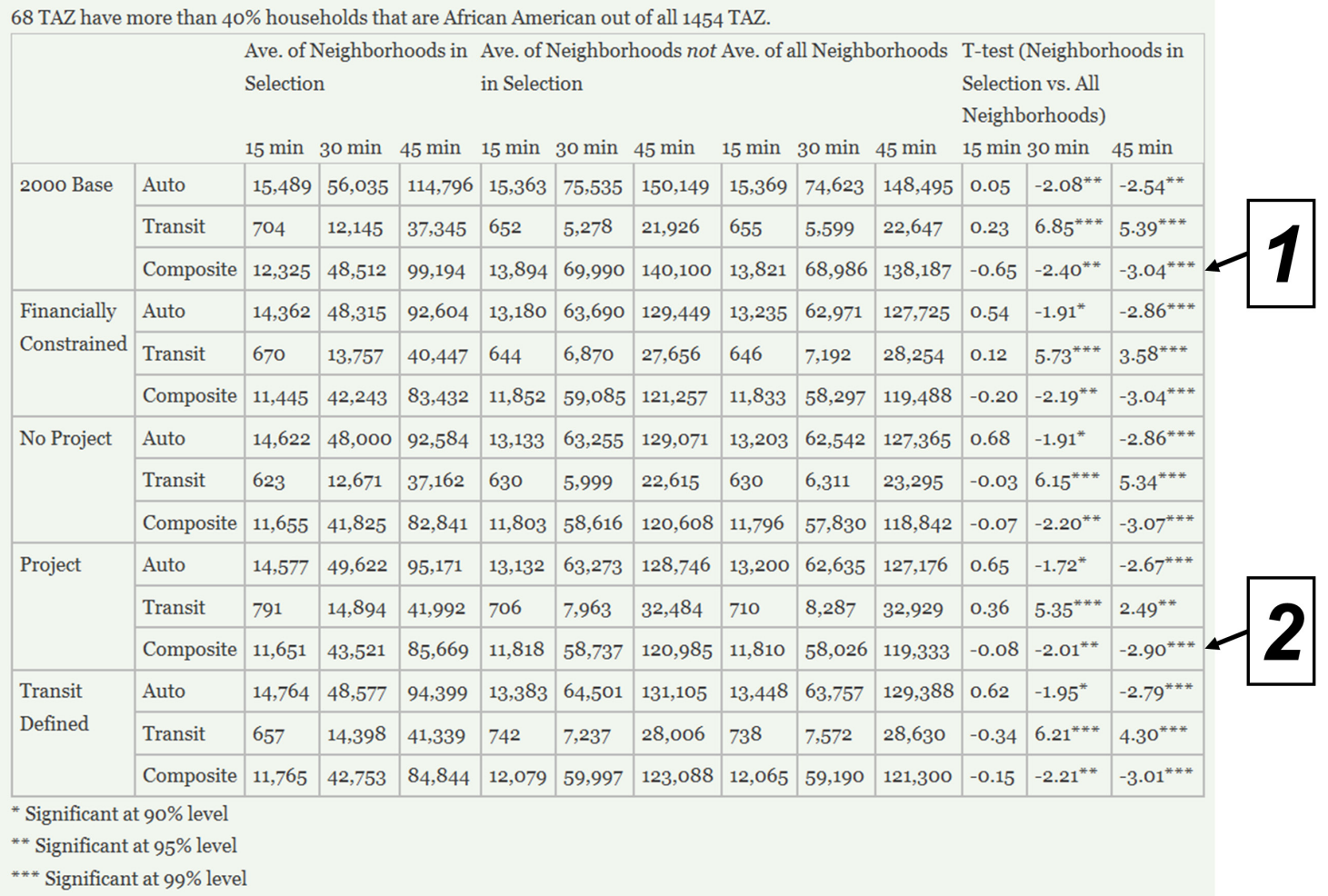

Figure 7: Table of accessibility to "manufacturing" jobs for neighborhoods with at least 40 percent African-American households

$91 \mathrm{TAZ}$ have more than $50 \%$ households that are below $200 \%$ Federal Poverty out of all $1454 \mathrm{TAZ}$. Ave. of Neighborhoods in Ave. of Neighborhoods not Ave. of all Neighborhoods T-test (Neighborhoods in Selection in Selection Selection vs. All Neighborhoods)

\begin{tabular}{|c|c|c|c|c|c|c|c|c|c|c|c|c|c|}
\hline & & $15 \mathrm{~min}$ & $30 \mathrm{~min}$ & $45 \mathrm{~min}$ & $15 \mathrm{~min}$ & $30 \mathrm{~min}$ & $45 \mathrm{~min}$ & $15 \mathrm{~min}$ & $30 \mathrm{~min}$ & $45 \mathrm{~min}$ & $15 \mathrm{~min}$ & $30 \mathrm{~min}$ & $45 \mathrm{~min}$ \\
\hline \multirow[t]{3}{*}{2000 Base } & Auto & 17,593 & 65,694 & 129,603 & 15,220 & 75,219 & 149,757 & 15,369 & 74,623 & 148,495 & 1.06 & -1.16 & -1.65 \\
\hline & Transit & 2,470 & 15,828 & 39,131 & 534 & 4,916 & 21,546 & 655 & 5,599 & 22,647 & $9.80^{* * *}$ & $12.41^{* * * *}$ & $7.00^{* * * *}$ \\
\hline & Composite & 11,524 & 49,095 & 97,342 & 13,974 & 70,314 & 140,914 & 13,821 & 68,986 & 138,187 & -1.15 & $-2.70^{* * *}$ & $-3.69^{* * *}$ \\
\hline \multirow{3}{*}{$\begin{array}{l}\text { Financially } \\
\text { Constrained }\end{array}$} & Auto & 16,435 & 57,271 & 109,859 & 13,022 & 63,352 & 128,918 & 13,235 & 62,971 & 127,725 & $1.76^{*}$ & -0.86 & $-1.68^{*}$ \\
\hline & Transit & 2,508 & 17,145 & 42,888 & 521 & 6,528 & 27,277 & 646 & 7,192 & 28,254 & $10.21^{* * *}$ & $10.07^{* * * *}$ & $4.98^{* * *}$ \\
\hline & Composite & 10,691 & 43,276 & 86,069 & 11,909 & 59,300 & 121,719 & 11,833 & 58,297 & 119,488 & -0.67 & $-2.37^{* *}$ & $-3.27^{* * *}$ \\
\hline \multirow[t]{3}{*}{ No Project } & Auto & 16,611 & 56,713 & 109,712 & 12,975 & 62,931 & 128,543 & 13,203 & 62,542 & 127,365 & $1.89^{*}$ & -0.89 & $-1.68^{*}$ \\
\hline & Transit & 2,433 & 16,239 & 39,169 & 509 & 5,648 & 22,235 & 630 & 6,311 & 23,295 & $9.93^{* * *}$ & $11.14^{* * *}$ & $7.09^{* * * *}$ \\
\hline & Composite & 10,801 & 42,671 & 85,100 & 11,863 & 58,842 & 121,094 & 11,796 & 57,830 & 118,842 & -0.59 & $-2.42^{* *}$ & $-3.34^{* * *}$ \\
\hline \multirow[t]{3}{*}{ Project } & Auto & 16,561 & 57,799 & 111,311 & 12,975 & 62,958 & 128,235 & 13,200 & 62,635 & 127,176 & $1.85^{*}$ & -0.74 & -1.53 \\
\hline & Transit & 2,813 & 18,557 & 47,499 & 569 & 7,601 & 31,956 & 710 & 8,287 & 32,929 & $10.69^{* * * *}$ & $9.64^{* * *}$ & $4.63^{* * *}$ \\
\hline & Composite & 10,911 & 43,841 & 88,335 & 11,870 & 58,973 & 121,403 & 11,810 & 58,026 & 119,333 & -0.52 & $-2.27^{* *}$ & $-3.10^{* * *}$ \\
\hline \multirow{3}{*}{$\begin{array}{l}\text { Transit } \\
\text { Defined }\end{array}$} & Auto & 16,713 & 57,512 & 111,274 & 13,230 & 64,174 & 130,597 & 13,448 & 63,757 & 129,388 & $1.80^{*}$ & -0.93 & $-1.67^{*}$ \\
\hline & Transit & 2,923 & 17,623 & 43,975 & 592 & 6,901 & 27,605 & 738 & 7,572 & 28,630 & $10.51^{* * *}$ & $10.60^{* * *}$ & $6.01^{* * * *}$ \\
\hline & Composite & 11,227 & 44,199 & 87,948 & 12,120 & 60,191 & 123,526 & 12,065 & 59,190 & 121,300 & -0.49 & $-2.33^{* *}$ & $-3.19^{* * * *}$ \\
\hline
\end{tabular}

Figure 8: Table of accessibility to "manufacturing" jobs for neighborhoods with at least 50 percent households with incomes below 200 percent federal poverty line 
Going to the "manufacturing" table (shown in Figure 7) shows the accessibility to the number of "manufacturing" jobs. For example, item one points to the T-score of -3.04 for the difference in "composite" accessibility within 45 minutes between the selected neighborhoods and all neighborhoods, for the 2000 Base scenario. Item two points to the T-score of -2.90 for the difference in "composite" accessibility within 45 minutes between the selected neighborhoods and all neighborhoods, for the project scenario. Both scores show that the 45-minute "composite" accessibility to "manufacturing" jobs is significantly lower for the selected neighborhoods than for all neighborhoods in the region.

Returning to the main accessibility calculator menu (Figure 3), we can also choose neighborhoods by income levels and automobile-ownership levels. Again, the percent of households is chosen first, followed by the characteristic. In this example, we seek to analyze the 91 neighborhoods with at least 50 percent of households below 200 percent of the federal poverty line.

Going to the "manufacturing" table (shown in Figure 8 below) shows the accessibility to the number of "manufacturing" jobs. For example, item one points to the T-score of -3.69 for the difference in "composite" accessibility within 45 minutes between the selected neighborhoods and all neighborhoods, for the 2000 base scenario. Item two points to the T-score of -3.10 for the difference in "composite" accessibility within 45 minutes between the selected neighborhoods and all neighborhoods, for the project scenario. Both scores show that the 45-minute "composite" accessibility to "manufacturing" jobs is significantly lower for the selected neighborhoods than for all neighborhoods.

\section{Discussion and conclusions}

Good public participation requires two-way communication: viewpoints from the public about decisions; and detailed data and information from planning agencies to assist the public in contributing to those decisions. Furthermore, civil rights and environmental justice planning directives require early, continuous, and transparent analysis in consultation with lowincome and minority communities protected under the Civil Rights Act, the EJ Order, and ensuing DOT directives. Protected communities should be able to understand how a project's proposals impact them specifically, and thus how the MPO can mitigate those impacts where significant. We have shown here that it is possible to create a tool to allow for a user-friendly inquiry into the accessibility outcomes of an RTP. Such a tool could be an important element for improving the public participation process in general, and specifically related to equity and justice issues, as it can be used to look at outcomes for specific groups protected by civil rights legislation. To be truly effective, however, it must be combined with a meaningful and ongoing two-way communication process with planning agencies, and an open and public process of creating and revising the contents of the RTP to meet community needs.

These results add to the debate on the equity outcomes of regional transportation investments. While there are more rigorous academic investigations into the distribution of regional accessibility, our tool is not meant to add to that debate but instead to improve on conventional equity analyses for RTPs. Existing analyses relied on region-wide measures to compare accessibility or other benefits between variously defined "communities of concern" and other groups (e.g., Southern California Association of Governments, 2008; Metropolitan Transportation Commission, 2009; Atlanta Regional Commission, 2011). Here, the user is able to define that community of concern more precisely and investigate access for specific destination types.

Developing new analysis tools is never without some drawbacks. There is a risk of "too much information," which in this case can lead to a bogging down of the planning process if stakeholders now are able to use this tool to champion their own narrow interests. This tool was developed in the admittedly narrow interest of improving measurement of accessibility impacts for those communities protected by civil rights law and related rules. One could argue that the regional planning and development process is full of narrow self-interests-some with better information and better connections to the regional decision-making process than others. An example would be a suburban county where congestion issues create barriers to local land development. The county commissioners, local land developers, etc. might be able to highlight their needs for freeway improvements in the process of regional transportation planning. Some of this would arise through the neutral process of regional transportation planning, but some of it would come through the regional politics of MPO boards, etc. Who does this kind of lobbying for urban transit riders? Often transit agencies are not seen either by themselves or by other political actors as particularly powerful or important to the regional planning process. This has often meant that urban transit riders have suffered from stagnating investments relative to the expanding places they need to access. It is a constant challenge to get all stakeholders on equal footing in the regional planning process and perhaps impossible as some will always have more resources and connections than others. Still, we need to think of new and innovative ways to open up the dialogue even if there are risks that the process could get bogged down.

There is also a risk that a tool of this nature, though geared 
for web-based access, is too technical for the general public to understand and could lead to misunderstandings of RTP benefits or burdens. This problem confronts all attempts to foster wider participation in complex policy-making processes. It is best addressed through efforts from advocates and allies of the communities with which we are concerned to build capacity in community leaders and members to understand these more technical issues. Our team has led several workshops with community members over the years on how the regional modeling process works and how to decipher modeling results. We also led one workshop on the use of this tool and to get feedback on our interface. The discussion yielded interesting insights: While some wanted to simplify the T-score results, others realized that this was an important issue that demanded to be understood and not overlooked. Indeed, T-scores are used in courts of law to prove disparities, and if communities are interested in highlighting disparities in their discussions with planners or within the legal process, T-scores hold a lot of weight and must be understood.

As this tool was informed by the requirements for better public input into planning decisions, we also hope that it can, in turn, inform those very requirements. In general, more specific measures of the impacts of RTPs would help inform debate about the distribution of the benefits and costs of RTPs. More specifically, MPOs could be required to allow more tailored outputs from RTP modeling efforts with the aim of improving understanding of benefits and costs for everyone, especially groups protected by civil rights law and related rules. In this vein, it is imperative that regional planning agencies give ample support toward data gathering, survey work, and other information gathering related to land use, destinations of various types, and demographics. Without this data, the understanding of the impacts and costs and benefits of regional transportation plans is crippled.

\section{Acknowledgements}

This work was funded by a grant from the Office of Civil Rights of the Federal Transit Administration (Grant \# MD26-8001-4) and was administered through the Urban Habitat Program in Oakland, California.

\section{References}

Atlanta Regional Commission (ARC). 2011. Draft Regional Transportation Plan PLAN 2040 - Comparative Analysis of PLAN 2040 Investments in Equitable Target Areas. Atlanta Regional Commission, Atlanta.

Beimbaum, E. 2006. A Transportation Modeling Primer. Center for Urban Transportation Studies. [Online] Available at: http://www4.uwm.edu/cuts/utp/models.pdf [Accessed October 12, 2010].

Benenson, I., K. Martens, Y. Rofe, and A. Kwartler. 2011. Public transport versus private car: GIS-based estimation of accessibility applied to the Tel Aviv metropolitan area. The Annals of Regional Science, 47(3): 499-515.

Bullard. R. 2004. The Anatomy of Transportation Racism. Highway Robbery: Transportation Racism and New Routes to Equity, R. Bullard, G. Johnson, and A. Torres. eds., Boston: South End Press, 15-32.Bullard, R. and G. Johnson. 1997. Just Transportation. Just Transportation: Dismantling race and class barrier to mobility, Stony Creek, Connecticut: New Society Publishers, 7-21.

Curtis, C. and J. Scheurer. 2010. Planning for sustainable accessibility: Developing tools to aid discussion and decisionmaking. Progress in Planning, 74: 53-106.

Denmark, D. 1998. The Outsiders: Planning and Transportation Disadvantaged. Journal of Planning Education and Research, 17: 231-245. doi: 10.1177/0739456X9801700304

El-Geneidy, A. and D. Levinson. 2006. Access to Destinations: Development of Accessibility Measures. Minnesota Department of Transportation, Office of Research Services. [Online] Available at: http://www.lrrb.org/pdf/200616.pdf [Accessed October 1, 2010].

Geurs, K.T. and J.R. Ritsema van Eck. 2001. Accessibility measures: review and applications. Evaluation of accessibility impacts of land-use transport scenarios and related social and economic impacts. RIVM - National Institute of Public Health and the Environment, Bilthoven, Netherlands.

Geurs, K.T. and B. van Wee. 2004. Accessibility evaluation of land-use and transport strategies: review and research directions. Journal of Transport Geography, 12: 127-140.

Forkenbrock, D.J. and J. Sheeley. 2004. Effective methods for environmental justice assessment. National Cooperative Highway Research Program Report 532. Washington, D.C.: Transportation Research Board. [Online] Available at: http://onlinepubs.trb.org/onlinepubs/nchrp/nchrp_ rpt_532.pdf [Accessed November 1, 2011]

Handy, S.L. and D.A. Niemeier. 1997. Measuring accessibility: An exploration of issues and alternatives. Environment and Planning A, 29: 1175-1194. 
Ihlanfeldt, K. and D. Sjoquist. 1998. The spatial mismatch hypothesis: a review of recent studies and their implications for welfare reform. Housing Policy Debate, 9: 849-892. doi: 10.1080/10511482.1998.9521321

Lucas, K. 2006. Providing transport for social inclusion within a framework for environmental justice in the UK. Transportation Research Part A: Policy and Practice, 40(10): 801-809. doi: 10.1016/j.tra.2005.12.005

Manaugh, K. and A. El-Geneidy. 2012. Who benefits from new transportation infrastructure? Using accessibility measures to evaluate social equity in transit provision. Accessibility and Transport Planning: Challenges for Europe and North America, K. Geurs, K. Krizek and A. Reggiani, eds., Cheltenham, UK: Edward Elgar. Martens, K. 2012. Justice in transport as justice in accessibility: applying Walzer's 'Spheres of Justice' to the transport sector. Transportation, 39(6): 1035-1053.

doi: $10.1007 / \mathrm{s} 11116-012-9388-7$

Martens, K. and A. Golub. 2012. A justice-theoretic exploration of accessibility measures. In K. Geurs, K. Krizek and A. Reggiani (Eds.), Accessibility and Transport Planning: Challenges for Europe and North America. , K. Geurs, K. Krizek, and A. Reggiani, eds., Edward Elgar, Cheltenham, UK.: Edward Elgar.

Martens, K., A. Golub and G. Robinson. 2012. A justice-theoretic approach to the distribution of transportation benefits: Implications for transportation planning practice in the United States. Transportation Research Part A: Policy and Practice 46(2): 684ר-695. doi:10.1016/j.tra.2012.01.004

Mavoa, S., K. Witten, T. McCreanor, and D. O'Sullivan. 2012. GIS based destination accessibility via public transit and walking in Auckland, New Zealand. Journal of Transport Geography, 20: 15-22.

Metropolitan Transportation Commission (MTC). 2005. Transportation 2030: Vision. [Online] Available at: http:/www.mtc.ca.gov/planning/2030_plan/downloads/ final_2030_plan/1-Vision.pdf [Accessed November 1, 2011]Metropolitan Transportation Commission (MTC). 2005a. Transportation 2030 Plan: Final Environmental Impact Report. [Online] Available at: http://www.mtc.ca.gov/ planning/2030_plan/downloads/EIR/EIR_FINAL.pdf

Metropolitan Transportation Commission (MTC). 2009. Equity Analysis Report for the Transportation 2035 Plan. [Online] Available at: http://www.mtc.ca.gov/planning/2035_plan/Supplementary/equity/FinalEquityAnalysisReportWeb.pdf [Accessed November 1, 2011]

Ong, P. and E.A. Blumenberg. 1998. Job access, commute and travel burden among welfare recipients. Urban Studies, 35(1): 77-93. doi: 10.1080/0042098985087
Pfeffer, N., F.H. Wen, H.M. Ikhrata, and J.R.Gosnell. 2002. Environmental justice in the transportation planning process-Southern California perspective. Transportation Research Record: Journal of the Transportation Research Board, 1792: 36-43.

Pucher, J. 1982. Discrimination in Mass Transit. Journal of the American Planning Association 48(3): 315-326. doi: 10.1080/01944368208976181

Purvis, C.L. 2000. "Data and Analysis Methods for Metropolitan-Level Environmental Justice Assessment." Transportation Research Record, 1756, 15-21.

Rose, M. 1990. Express Highway Politics, 1939-1989. Knoxville, Tennessee: University of Tennessee Press.

Sanchez, T., R. Stolz, and J.S. Ma. 2003. Moving to Equity: Addressing Inequitable Effects of Transportation Policies on Minorities. Cambridge, Massachusetts: The Civil Rights Project at Harvard University. [Online] Available at: http:// civilrightsproject.ucla.edu/research/metro-and-regional-inequalities/transportation/moving-to-equity-addressing-inequitable-effects-of-transportation-policies-on-minorities/ sanchez-moving-to-equity-transportation-policies.pdf [Accessed Nov 1, 2011]

Southern California Association of Governments (SCAG). (2008). 2008 Regional Transportation Plan: Environmental Justice Report. [Online] Available at: http://rtpscs.scag. ca.gov/Documents/2008/fEnvironmentalJustice.pdf [Accessed Oct 1, 2011]

Taylor, B.D. and P.M. Ong. 1995. Spatial mismatch or automobile mismatch? An examination of race, residence and commuting in US metropolitan areas. Urban Studies 32(9): 1453-1473. doi: 10.1080/00420989550012348

Transdef. 2012. The TRANSDEF Smart Growth Alternative. [Online] Available at: http://transdef.org/RTP/RTP.html [Accessed October 1, 2011]

Tribby, C.P. and P.A. Zandbergen. 2012. High-resolution spatio-temporal modeling of public transit accessibility. $A p$ plied Geography, 34: 345-355

Wachs, M. and T.G. Kumagai. 1973. Physical Accessibility as a Social Indicator. Socio-Economic Planning Science, 7: 437-456.

van Wee, B. and K. Geurs. 2011. Discussing Equity and Social Exclusion in Accessibility Evaluations. European Journal of Transport and Infrastructure Research, 11(4): 350-367. 


\section{Legislation and directives cited}

DOT (Department of Transportation). 2012. Order 5610.2(a) Department of Transportation Actions to Address Environmental Justice in Minority Populations and Low-Income Populations (May 2, 2012) [Online] http://www.fhwa. dot.gov/environment/environmental_justice/ej_at_dot/ order_56102a/ [Accessed March 3, 2013]

Executive Order 12898. 1994. Federal Actions to Address Environmental Justice in Minority Populations and LowIncome Populations, 59 Fed. Reg 7629 (section 1-101) (1994), 3 C.F.R. S 859, reprinted in 42 U.S.C. S4321. [Online] http://www.epa.gov/fedsite/eo12898.htm [Accessed October 1, 2010]

FHWA (Federal Highway Administration). 2012. Order 6640.23A entitled FHWA Actions to Address Environmental Justice in Minority Populations and Low-Income Populations (June 14, 2012) [Online] http://www.fhwa. dot.gov/legsregs/directives/orders/664023a.htm [Accessed March 3, 2013]

FTA. 2012. Circular 4702.1B, Title VI Requirements and Guidelines for Federal Transit Administration Recipients. [Online] http://www.fta.dot.gov/laws/circulars/leg reg_5956.html [Accessed March 3, 2013] 